\title{
CONTAMINAÇÃO DE SEDIMENTOS DE FUNDO NAS BACIAS DE CAPTAÇÃO DE ABASTECIMENTO PÚBLICO DE CAXIAS DO SUL, RS
}

\author{
CONTAMINATION OF BOTTON SEDIMENTS IN THE WATERSHEDS OF PUBLIC SUPPLY IN \\ CAXIAS DO SUL, RS
}

\author{
Tiago de VARGAS ${ }^{1,2}$; Ari ROISENBERG ${ }^{1}$; Fernando Hepp PULGATI ${ }^{3}$ \\ ${ }^{1}$ Instituto de Geociências, Universidade Federal do Rio Grande do Sul, Porto Alegre - Brasil. \\ Email: vargas.geo@gmail.com; ari.roisenberg@ufrgs.br \\ ${ }^{2}$ Serviço Autônomo Municipal de Água e Esgoto (SAMAE), Caxias do Sul - RS. Email: tvargas@samaecaxias.com.br \\ ${ }^{3}$ Instituto de Matemática e Estatística, Universidade Federal do Rio Grande do Sul, Porto Alegre - RS - Brasil. \\ Email: pulgati@ufrgs.br

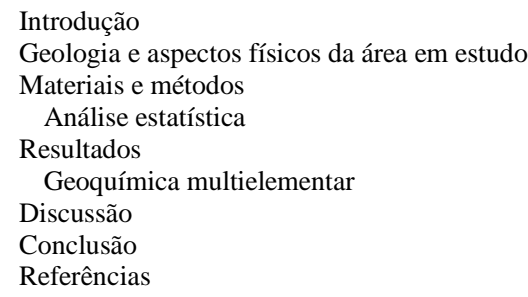

RESUMO - O presente estudo caracterizou a geoquímica dos sedimentos finos de fundo de arroios monitorados nas bacias de captação Faxinal e Maestra, Município de Caxias do Sul, RS, tendo como objetivo correlacionar os resultados de geoquímica multielementar com a rocha-fonte presente na área e a composição dos principais fertilizantes utilizados nas áreas agrícolas. Coletouse amostras de sedimentos e de fertilizantes, que foram analisados por diferentes técnicas (granulometria, difração de Raios-X e ICPMS). Os resultados obtidos foram interpretados com suporte de estatística descritiva e multivariada (Análise de Componentes Principais e Análise Fatorial), relacionando com o fator de enriquecimento. A granulometria indicou que os arroios possuem um sistema fluvial dinâmico com eventos de alta energia. A difração de Raios-X identificou a caolinita como argilomineral predominante. O fator de enriquecimento e os dados estatísticos sinalizaram discrepâncias geoquímicas para o $\mathrm{Pb}, \mathrm{Sn}, \mathrm{Cr}, \mathrm{Ni}, \mathrm{Cu}$ e Na. Os Elementos Terras Raras identificados nos sedimentos apresentaram razão média de $(\mathrm{La} / \mathrm{Lu})_{\mathrm{N}}=5,39$ e intervalo de variação IQR $(\mathrm{La} / \mathrm{Lu})_{\mathrm{N}}$ de 2,46 à 8,41. Os sedimentos de corrente dos córregos da bacia de captação Faxinal expõem contaminação e efeito acumulativo por metais pesados provenientes da aplicação de fertilizantes e fungicidas, enquanto que o excesso de sódio nos sedimentos da bacia de captação Maestra são resultantes da descarga direta de esgoto doméstico no recurso hídrico.

Palavras-chave: geoquímica ambiental, contaminação, chumbo, sedimentos, bacia hidrográfica.

\begin{abstract}
This study characterized the geochemistry of fine sediments of botton of streams monitored in the catchment Faxinal and Maestra, the town of Caxias do Sul, RS, aiming to correlate the results of multi-element geochemistry with the source rock present in the area and the composition of the main fertilizers used in farming areas. Sediment and fertilizers samples were collected, and were analyzed by different techniques (particle size, X-ray diffraction and ICP-MS). The results were interpreted with descriptive and multivariate statistical support (Principal Component Analysis and Factor Analysis), and related to the enrichment factor. The particle size indicated that the streams have a dynamic water system with high energy events. The diffraction of X-rays identified the clay mineral kaolinite as predominant. The enrichment factor and the statistical data signaled geochemical outliers for the $\mathrm{Pb}, \mathrm{Sn}, \mathrm{Cr}, \mathrm{Ni}, \mathrm{Cu}$ and Na. The Rare Earth Elements identified in sediments showed an average ratio $(\mathrm{La} / \mathrm{Lu})_{\mathrm{N}}=5.39 \mathrm{and} \mathrm{IQR}$ range $(\mathrm{La} / \mathrm{Lu})_{\mathrm{N}} 2.46$ to 8.41. The sediments of fund of streams of Faxinal catchment show contamination and cumulative effect of heavy metals from the application of fertilizers and fungicides, while the excess sodium in the sediments of Maestra catchment area are the result of direct discharge of domestic sewage in the streams.
\end{abstract}

Keywords: environment geochemistry, contamination, lead, sediments, watershed.

\section{INTRODUÇÃO}

O incremento do consumo da água e a contaminação por efluentes domésticos, industriais e insumos agrícolas estão diretamente relacionados ao crescimento da população. A expansão agrícola provoca o acréscimo de insumos químicos em áreas cada vez mais extensas, ocasionando preocupação ao equilíbrio químico dos solos e águas. A elevação da concentração de metais pesados nos sedimentos de fundo dos rios está relacionada à ausência de manejo apropriado dos solos agrícolas e à carência de tratamento adequado de efluentes, tanto em áreas rurais quanto urbanas.
Conforme Torres et al. (2005), a pesquisa geoquímica em sedimentos é justificada pelo uso indiscriminado de agrotóxicos, fertilizantes e defensivos químicos na atividade agrícola.

A análise multielementar pode servir como indicador da influência de contaminantes de origens antrópicas no ambiente geoquímico natural e relacionar as possíveis fontes. Indicadores ambientais são utilizados para monitorar o estágio de evolução do meio ambiente em relação ao desenvolvimento sustentável e ameaças ambientais (Charalampides et al., 2002). 
Na bacia hidrográfica do rio Salitre, Estado da Bahia, foram identificadas elevadas concentrações de metais pesados nos solos e nos sedimentos depositados próximos as áreas de irrigação agrícola, destacando-se cobre, zinco e chumbo. Já no rio São Francisco os valores destes metais pesados apresentaram níveis muito tóxicos para a maioria dos seres vivos (Brito et al., 2004).

Estudo realizado na bacia hidrográfica do ribeirão Caraça, Minas Gerais, caracterizou a geoquímica das águas e sedimentos para determinar a influência das atividades antrópicas. Os resultados demonstraram que o uso e ocupação do solo têm influência direta na qualidade das águas da região, enquanto os sedimentos refletem alterações significativas em pontos imediatamente a jusante das áreas com mineração (Mendes et al., 2013).

O Município de Caxias do Sul possui uma população de 435.482 habitantes, sendo 419.321 urbana e 16.161 rural. O posicionamento geográfico está entre as coordenadas

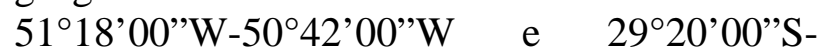
28 48'00"S. A bacia de captação do arroio Faxinal abastece $63 \%$ da população urbana do município, representando o principal manancial superficial. Possui área de captação hidrográfica de 6.679 ha, cujo uso é predominantemente rural. A bacia de captação do Arroio Maestra abastece cerca de $20 \%$ da população urbana e possui uma área de contribuição de 1.527 ha, sendo parte urbana e parte rural (Figura 1).

$\mathrm{O}$ presente estudo tem como objetivo correlacionar a geoquímica dos sedimentos finos de fundo dos arroios monitorados com a rocha-fonte e a composição dos principais fertilizantes utilizados nas áreas agrícolas. Esta associação será demonstrada através de tratamento estatístico descritivo e análise multivariada, verificando se há contribuição antrópica na composição química dos sedimentos transportados aos reservatórios de abastecimento público.
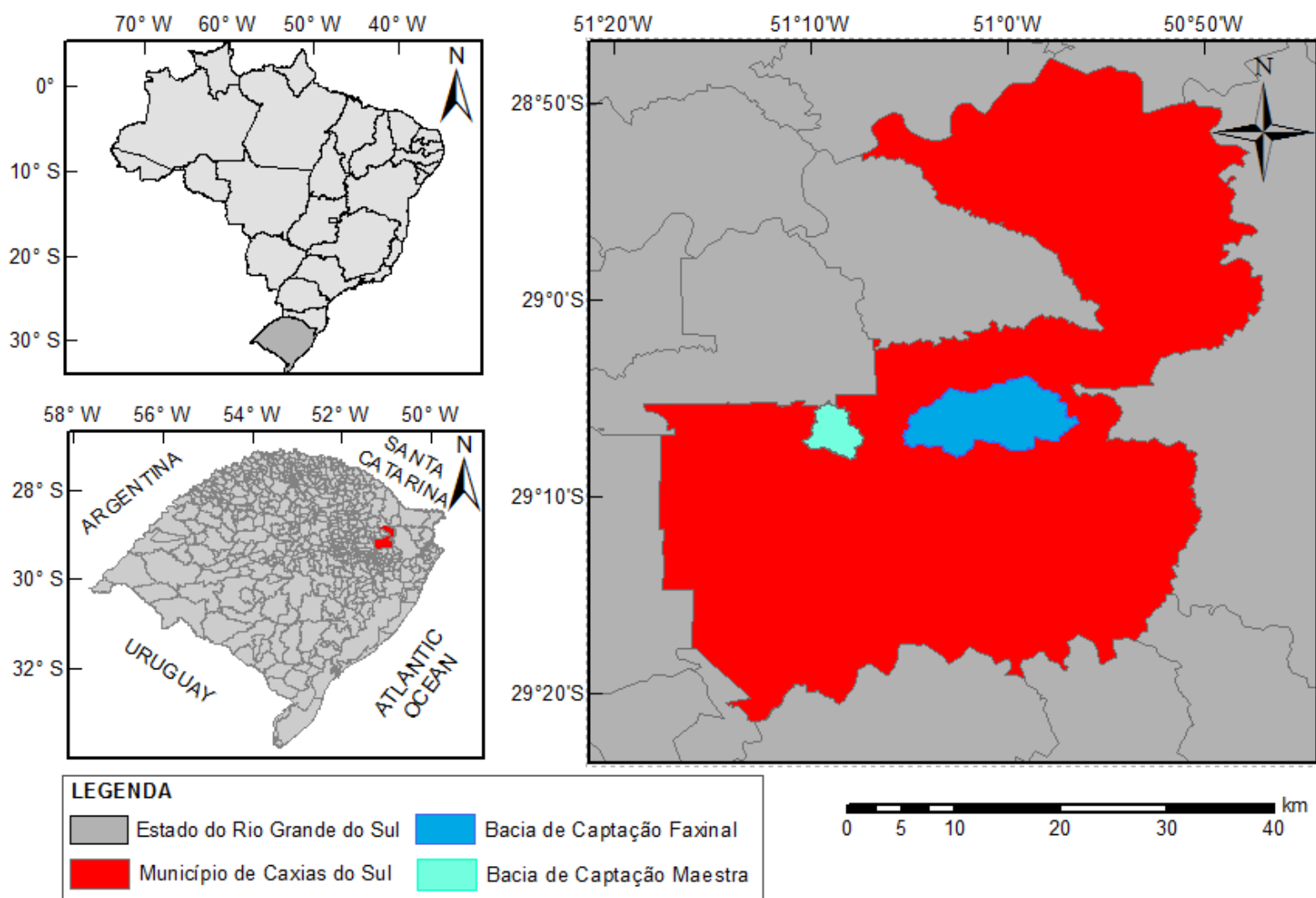

Figura 1 - Localização das bacias de captação Faxinal e Maestra, Município de Caxias do Sul (Datum SIRGAS 2000, Zona 22, Fuso J)

\section{GEOLOGIA E ASPECTOS FÍSICOS DA ÁREA EM ESTUDO}

A área de estudo está inserida na bacia intracratônica da Província Paraná que detém o Grupo São Bento, este composto pelas unidades sedimentares das Formações Guará e Botucatu e pelo pacote vulcânico da Formação Serra Geral, relacionado com a abertura do Atlântico Sul. 
As litologias que constituem 0 pacote vulcânico são representadas por derrames de basaltos toleíticos a andesibasaltos, na base da sequência, e riodacitos, riolitos e dacitos, dominantemente na porção superior.

Nestes últimos, são reconhecidos dois tipos, denominados como Palmas - afírico e Chapecó - porfirítico (Bellieni et al., 1984; IBGE, 1986; Bellieni et al., 1986; Roisenberg, 1990; Roisenberg \& Viero, 2000). A fração ácida do vulcanismo da Formação Serra Geral ocorre dominantemente como unidades Vulcanoclásticas relacionadas com modelos ignimbríticos (Roisenberg, 1990; Roisenberg \& Viero, 2000), havendo registros locais de domos cuja distribuição areal é bastante restrita (Lima et al. 2012).

Na região metropolitana de Caxias do Sul predomina em superfície as unidades ácidas ignimbríticas do tipo Palmas, fácies Caxias (Peate, 1997; Nardy, 2008).

No conjunto, alcançam espessuras da ordem de 300 metros, registrando-se intercalações de derrames de basaltos nas porções da base da sequência. A resistência ao intemperismo das vulcânicas ácidas gera solos rasos, que podem localmente apresentar espessuras maiores nas zonas afetadas por tectonismo e sujeitas à percolação de água.

A análise de imagens de satélites em várias bandas permite demonstrar que a tectônica rígida da região é intensa, com lineamentos cuja direção predominante é NE-SW, sendo os lineamentos de NW-SE e E-W menos expressivos (Betiollo, 2006).

Todos os lineamentos tectônicos verificados na área metropolitana de Caxias do Sul relacionam-se a eventos de natureza distensional e são ressaltados na disposição das redes de drenagem que ocorrem neles encaixadas e exibem quedas bruscas de curso. Estruturas representadas por lineamentos com orientação N40E estão relacionadas geneticamente com os padrões estruturais do Cinturão Móvel Dom Feliciano e com o sistema de falhas NE - SW (Frasca \& Lisboa, 1993). A Falha Caxias transpassa os limites da cidade, possuindo direção
NNE /SSW e extensão aproximada de $70 \mathrm{~km}$. Os lineamentos mapeados são, em geral, de pequeno porte, sendo observada uma estrutura de grande porte (Falha Caxias), que transpassa o reservatório da represa Maestra.

Nas bacias de captação das represas Faxinal e Maestra ocorrem unidades ácidas do tipo Palmas, representando a parte central e a zona bandada da camada, constituídas por rochas afíricas com raros microfenocristais de plagioclásio e clinopiroxênio imersos numa matriz microcristalina a subvítrea, com abundantes intercrescimentos quartzo-feldspáticos e micrólitos de plagioclásio, piroxênio, anfibólio e magnetita.

Os solos da região de Caxias do Sul compreendem Neossolos, Cambissolos, Argissolos, Latossolos, Nitossolos e Chernossolos háplicos órticos (Streck et. al., 2008). Na área específica de estudo foram identificados Neossolos Regolíticos apresentando horizonte A assentado sobre a rocha totalmente alterada e contato lítico em profundidade maior do que 50 cm. Observa-se associações entre os solos tipo Neossolo, Cambissolo e Argissolo. Esta relação está vinculada ao processo de maturidade do solo. Em alguns perfis foram identificados depósitos de talus e colúvios.

O Município de Caxias do Sul está inserido na Região Hidrográfica do Guaíba, Bacias Hidrográficas Taquari-Antas (G040) e Caí (G030). Estas bacias abrangem parte das unidades geomorfológicas Planalto dos Campos Gerais e Serra Geral. As bacias de captação Faxinal e Maestra estão inseridas na Bacia Hidrográfica Taquari-Antas, sendo tipificadas como contribuintes do Rio das Antas. A Bacia Taquari-Antas pode ser caracterizada por regimes torrenciais, de escoamentos superficiais rápidos e bruscas variações de descargas, por apresentar declividade média elevada, rede de drenagem densa, pouca cobertura vegetal, pouca profundidade e baixa permeabilidade dos solos. O clima na região é classificado como temperado quente e apresenta chuva média de $1.915 \mathrm{~mm}$ anuais (Rio Grande do Sul, 2010).

\section{MATERIAIS E MÉTODOS}

O uso do solo foi caracterizado através de Sistema de Informação Geográfica (SIG) analisando imagens de satélite coletadas pelo
Geo Eye (2011), diferenciando áreas urbanas e rurais, preliminarmente selecionadas no software ArcGIS. 
Foram realizadas visitas aos agricultores executando cadastro, amostragem de fertilizantes (NPK, Nitrato de Cálcio e corretivo de solo), identificação dos agrotóxicos mais utilizados e tipos de culturas agrícolas.

A bacia de captação Faxinal foi seccionada em sete sub-bacias, cada uma correspondendo a um ponto de monitoramento (Fx-01, Fx-02, Fx03, Fx-04, Fx-05, Fx-06 e Fx-07), enquanto a bacia de captação Maestra foi dividida em duas sub-bacias (Ma-01 e Ma-02).

Os pontos de background correspondem a Fx-BR e Ma-BR. A quantificação do pico de vazão extrema foi registrada por linígrafo de pressão com cabo sensor Wika, software Log Chart II e datalogger Novus com capacidade de

\subsection{0 registros.}

Os locais de amostragem foram determinados em posições estratégicas nos tributários que fornecem aporte hídrico aos reservatórios e em dois sítios sem influência antrópica para estabelecimento do branco geoquímico/ background (Figura 2).

Amostragem ocorreu em período após a fertilização do solo, correspondente ao mês de junho de 2012. A coleta de material foi realizada de modo a extrair várias amostras de material do leito do curso d’água, cujo número e disposição é decorrente da dimensão da secção transversal. Com isto, foi obtida uma amostragem composta para cada ponto que era posteriormente quarteada em laboratório.

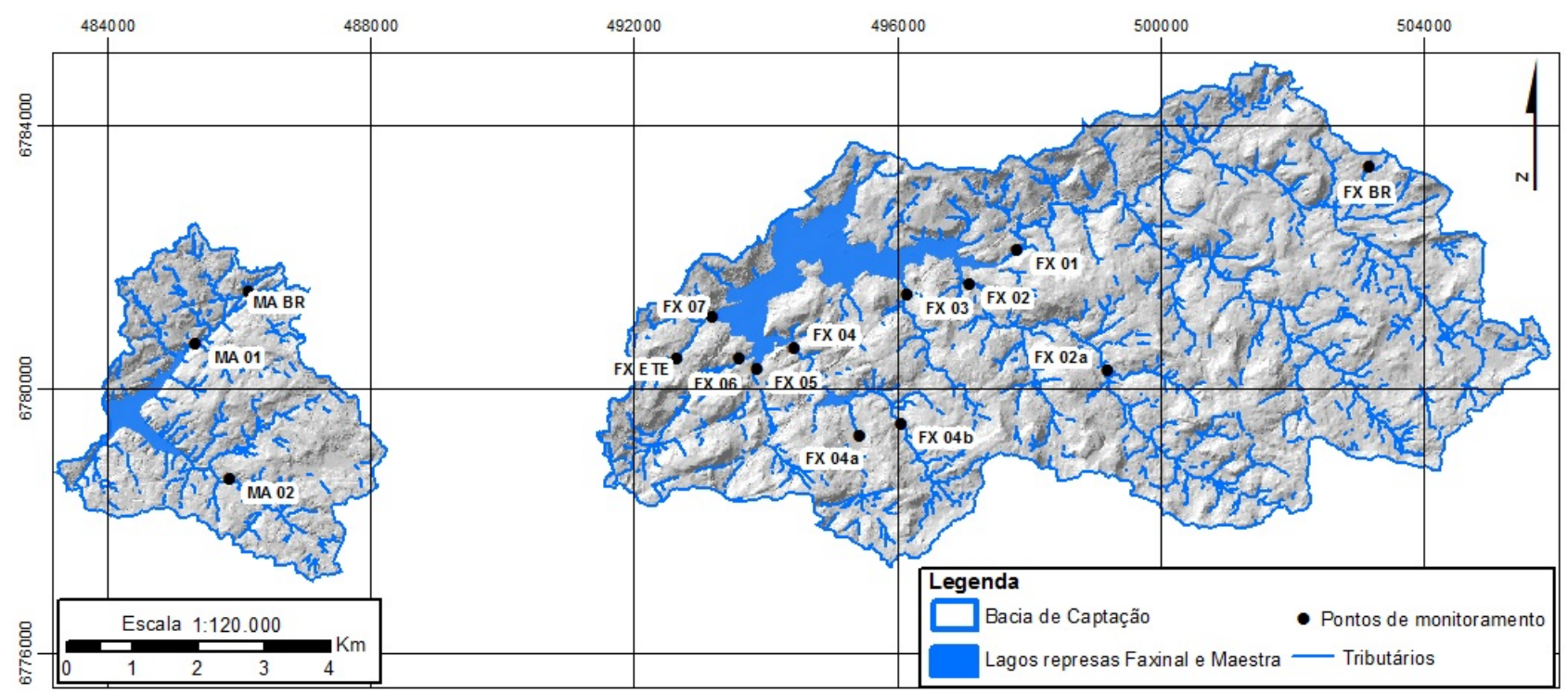

Figura 2 - Mapa de localização dos pontos de amostragem nas bacias de captação Maestra e Faxinal (Datum SIRGAS 2000, Zona 22, Fuso J).

As alíquotas de sedimentos foram secas à temperatura de $60^{\circ} \mathrm{C}$, sendo pulverizadas em gral de porcelana e separadas em peneira de malha de nylon de 0,062 $\mathrm{mm}$ a úmido.

A fração mais fina foi colocada em recipiente contendo $1 \mathrm{~L}$ de água destilada, adicionando-se pirofosfato de sódio como antidispersante, enquanto a mais grossa foi separada em várias granulometrias. A fração argila foi analisada com uso de Difratômetro de Raios-X Siemens Bruker AXS do Instituto de Geociências da UFRGS.

Os sedimentos foram acondicionados em sacos plásticos, congelados e enviados ao laboratório de caracterização de águas da Pontifícia Universidade Católica do Rio de Janeiro para análise de elementos maiores ( $\mathrm{Na}$, $\mathrm{K}$, Ca, $\mathrm{Mg}, \mathrm{Al}$ e $\mathrm{Fe}$ ) por ICP-OES e os elementos-traço por ICP-MS.

O cálculo do fator de enriquecimento (FE) dos contaminantes foi normalizado pelo $\mathrm{Al}$ medido, que apresenta relativa imobilidade em processos supergênicos, de acordo com a equação (Sutherland, 2000):

$$
F E=\frac{\left[C_{n(\text { amostra })} / C_{A l(\text { amostra })}\right]}{\left[C_{n(\text { Background })} / C_{A l(\text { Background })}\right]}
$$

O referido autor identifica os seguintes intervalos: FE $<2$ - depleção a mínimo de sinal antropogênico; FE entre 2 e 5 sinal antropogênico moderado; entre 5 e 20 sinal antropogênico significativo; entre 20 e 40 sinal antropogênico muito forte e $>40$ sinal antropogênico extremo.

Os elementos utilizados no fator de 
enriquecimento foram: $\mathrm{B}, \mathrm{Na}, \mathrm{Mg}, \mathrm{Al}, \mathrm{K}, \mathrm{As}$, $\mathrm{Ba}, \mathrm{Ca}, \mathrm{Cd}, \mathrm{Fe}, \mathrm{Mn}, \mathrm{Sr}, \mathrm{Ti}, \mathrm{V}, \mathrm{Cr}, \mathrm{Sc}$, Se, Mo, $\mathrm{Sn}, \mathrm{Cu}, \mathrm{Ni}, \mathrm{Co}, \mathrm{Zn}, \mathrm{Pb}$ e os Elementos das Terras Raras La, Nd, Sm, Eu, Gd, Tb, Dy, Ho, Er, Tm, Yb e Lu.

\section{Análise Estatística}

A compreensão da distribuição dos elementos químicos na bacia foi embasada através de estudos de análise estatística descritiva e de análise multivariada dos dados.

$\mathrm{Na}$ análise descritiva foram determinados os valores de entrada mínima, entrada máxima, primeiro quartil $\left(\mathrm{Q}_{1}\right)$, terceiro quartil $\left(\mathrm{Q}_{3}\right)$ e mediana. Para obter a medida de variação amostral foi determinada a Amplitude Interquartil ( IQR $\left.=Q_{3}-Q_{1}\right)$ que relaciona à diferença entre o terceiro e primeiro quartil. $\mathrm{O}$ IQR pode ser utilizado para identificar valores discrepantes. Aplicando a equação $\mathrm{Q}_{3}+$
1,5*IQR e $\mathrm{Q}_{1}-1,5 *$ IQR é possível identificar o intervalo de valores concordantes, já quantias externas são consideradas discrepantes (Larson, 2010).

Análise estatística multivariada foi realizada através do software SPSS versão 18. A aplicação do método Análise Componentes Principais (ACP) adotou dados com autovalores acima de 1 e variância acumulada em torno de $70 \%$, conforme Kaiser (1958). Para facilitar a interpretação dos resultados foi utilizado o método de rotação ortogonal Varimax com normalização de Kaiser.

Criou-se os gráficos 2d relacionando os autovetores através da Análise Fatorial (AF). Por fim, a análise de agrupamento foi realizada pelo método hierárquico de variância mínima (Ward) e demonstrada graficamente por dendrograma horizontal.

\section{RESULTADOS}

A bacia de captação Faxinal apresenta $14,85 \%$ da área total em uso agrícola. As principais culturas agrícolas identificadas são alho, ameixa, beterraba, brócolis, caqui, cenoura, maçã, milho, pera, rabanete, repolho, tomate e videira.

As maiores áreas em valor absoluto observadas com cultivo ocorrem nas sub-bacias Fx-01 e Fx-02 (Tabela 1). A sub-bacia Fx-07 representa a maior porcentagem de área edificada (2,25\%) e possui estação de tratamento de esgoto localizada próxima à área urbanizada. Na bacia de captação Maestra a sub-bacia representada pelo ponto Ma-02 demonstra uso do solo com elevada porcentagem de edificações, enquanto no ponto Ma-01 a proporção para uso agrícola é maior que a edificada (Tabela 1).

A figura 3 apresenta a distribuição do uso agrícola e das edificações nas bacias estudadas.

Tabela 1 - Quantificação das áreas de uso agrícola, edificações, mata e campos em cada sub-bacia das bacias de captação Faxinal (Fx) e Maestra (Ma).

\begin{tabular}{l|c|c|c|c|c}
\hline $\begin{array}{l}\text { Pontos } \\
\text { sub-bacias }\end{array}$ & $\begin{array}{c}\text { Área sub-bacias } \\
\text { (ha) }\end{array}$ & $\begin{array}{c}\text { Uso agrícola } \\
\text { (ha) }\end{array}$ & $\begin{array}{c}\text { Uso agrícola } \\
\text { (\%) }\end{array}$ & $\begin{array}{c}\text { Área edificada } \\
\text { (\%) }\end{array}$ & $\begin{array}{c}\text { Área mata e campo } \\
\text { (ha) }\end{array}$ \\
\hline Fx-01 & $2.910,71$ & 332,22 & 11,41 & 0,27 & 2.567 \\
\hline Fx-02 & $1.206,90$ & 334,26 & 27,70 & 0,36 & 867,6 \\
\hline Fx-03 & 195,65 & 42,13 & 21,53 & 0,37 & 152,8 \\
\hline Fx-04 & 684,09 & 156,13 & 22,8 & 1,28 & 517,1 \\
\hline Fx-05 & 282,87 & 28,22 & 9,98 & 0,63 & 252,8 \\
\hline Fx-06 & $1.239,33$ & 80,34 & 6,48 & 0,83 & 1.148 \\
\hline Fx-07 & 159,74 & 18,43 & 11,54 & 2,25 & 137,7 \\
\hline Total & $6.679,29$ & 991,72 & 14,85 & 0,56 & 5.644 \\
\hline Ma-01 & 403,34 & 44,72 & 11,08 & 1,32 & 353,2 \\
\hline Ma-02 & 358,75 & 20,36 & 5,67 & 32,44 & 221,9 \\
\hline Total & 762,09 & 65,08 & 8,53 & 15,97 & 575,1 \\
\hline
\end{tabular}

Os resultados granulométricos estabelecem predominância do tamanho areia e cascalho, indicando de forma subordinada a fração lodosa. Conforme os diagramas ternários de Folk as amostras foram classificadas para texturas de sedimentos grosseiros e finos. No diagrama principal $50 \%$ das amostras são classificadas na fração cascalho (Ca, Cal) sugerindo sistema com alta taxa de energia para transporte (Figura 4).

O diagrama complementar para sedimentos finos descreve predominância das texturas areia 
argilosa e lodosa indicando coesão entre os grãos e possível existência de fenômenos de adsorção e absorção na carga sedimentar (Figura 5).

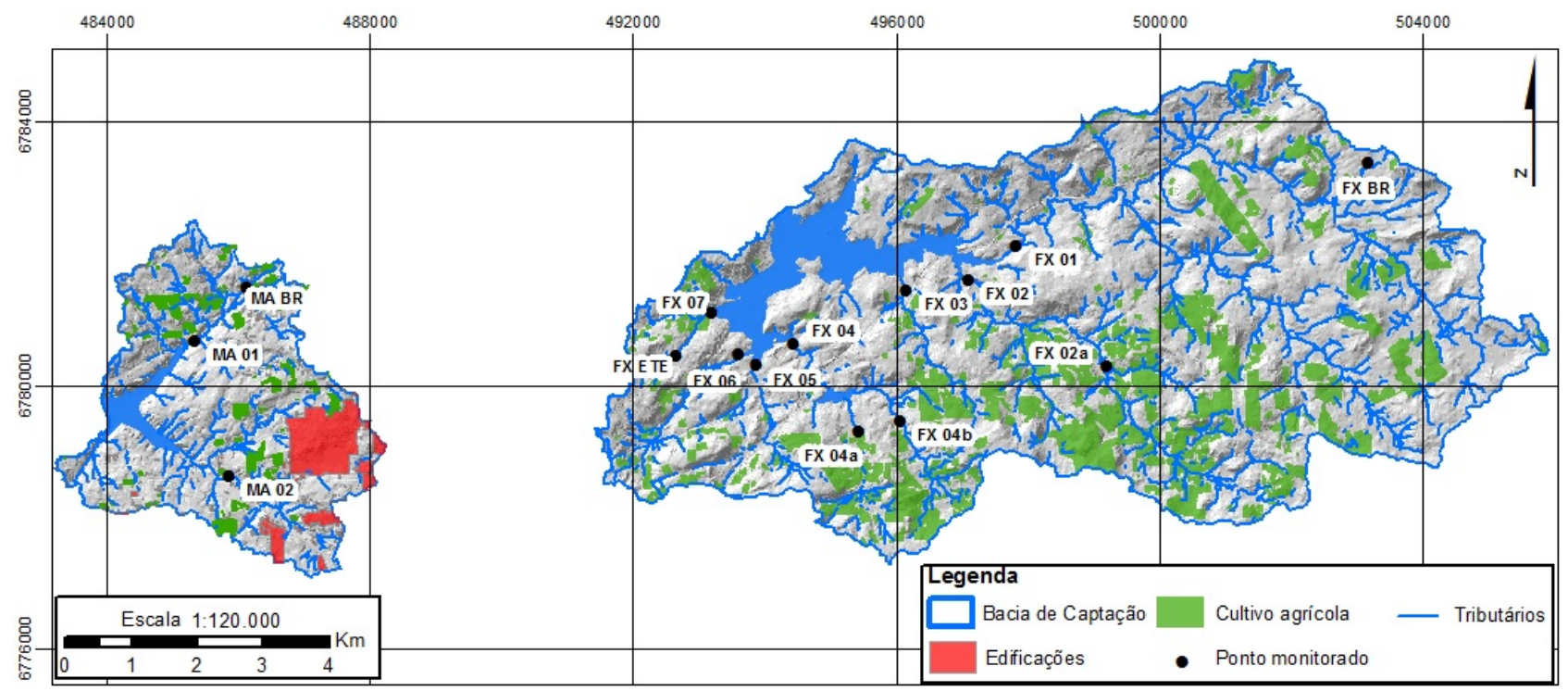

Figura 3 - Mapa de uso do solo nas bacias de captação Maestra e Faxinal (Datum SIRGAS 2000, Zona 22, Fuso J).

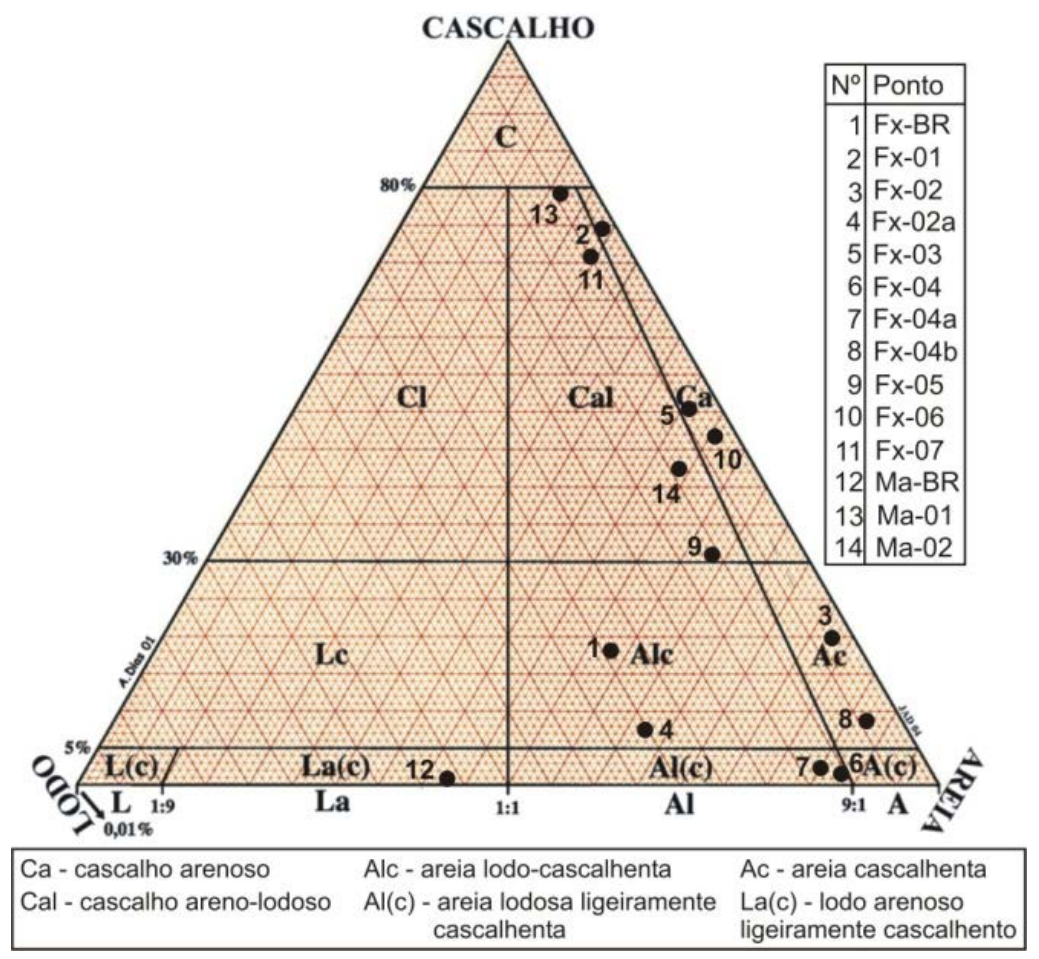

Figura 4 - Classificação da textura grosseira, conforme diagrama de Folk.

A configuração granulométrica analisada decorre de fatores físicos locais como geologia, fontes de sedimentos proximais e ambientes fluviais lóticos com períodos de eventos extremos, envolvendo alta energia hídrica. A distribuição granulométrica heterogênea observada retrata tributários com leitos dinâmicos e pouco tempo de permanência da carga sedimentar de fundo.

Os valores observados no linígrafo instalado no arroio Faxinal demonstraram a maior vazão de cheia registrada de $122,28 \mathrm{~m}^{3} \cdot \mathrm{s}^{-1}$, atingindo a cota de 2,27 m. As alíquotas coletadas para background (Fx-BR e Ma-BR) expuseram maior porcentagem de lama, condizente com trechos proximais às nascentes, baixa declividade do leito e velocidade lenta e uniforme do fluxo das águas. Segundo Cunha (2007), estas características constituem fluxo laminar com baixo processo erosivo e capacidade erosiva, refletindo no deslocamento de partículas muito finas.

A análise da fação de argilominerais por difratometria de Raios-X registrou em todas as 
amostras analisadas o amplo predomínio de caolinita.

Este argilomineral tem origem na alteração dos silicatos das rochas vulcânicas em condições ácidas. A caolinita possui baixa capacidade de troca de íons (3-15 meq/100g), no entanto, a capacidade de sorção está vinculada à sua superfície de carga, que é fortemente dependente do $\mathrm{pH}$ e das reações de interação solvente-solução.

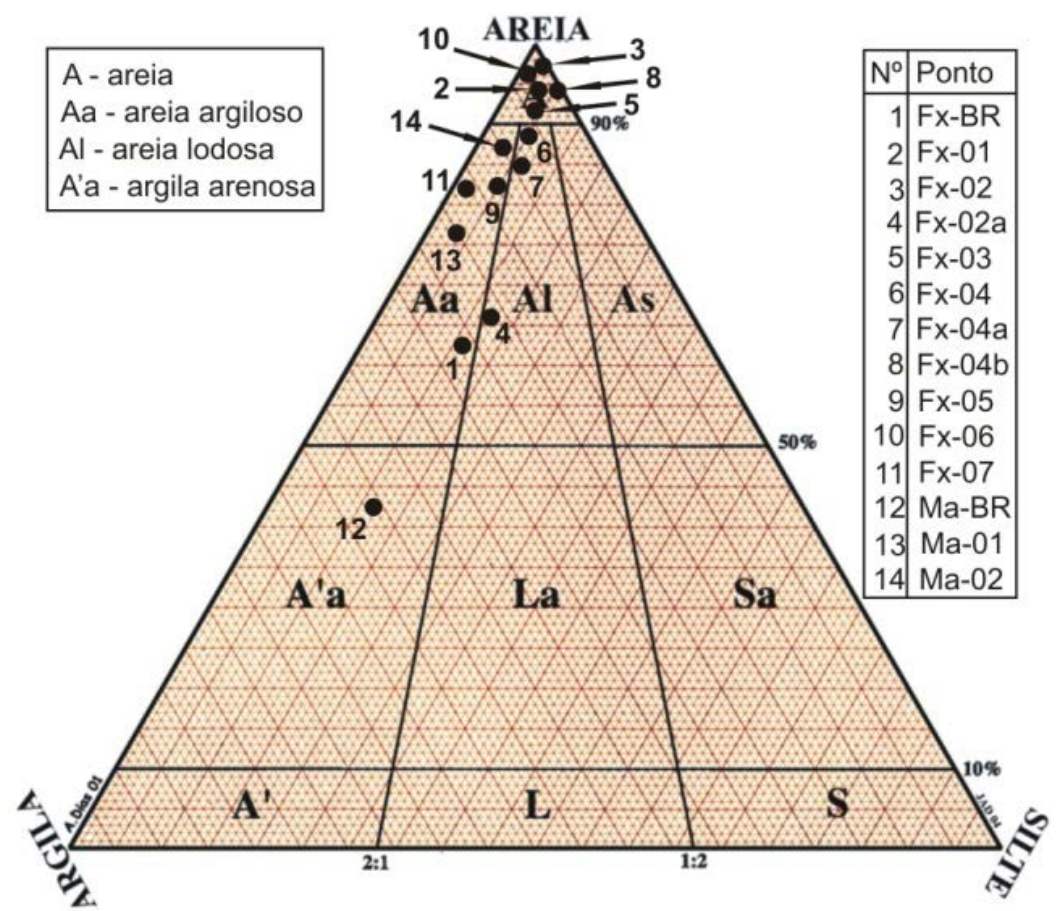

Figura 5 - Classificação da textura para finos, conforme diagrama de Folk.

No caso do chumbo, p. ex, o aumento do $\mathrm{pH}$ pode se refletir em maior sorção do complexo $\mathrm{PbOH}^{+}$do que o íon livre $\mathrm{Pb}^{+2}$, devido à maior capacidade de troca de ânions $\left(\mathrm{OH}^{-}\right)$. Os solos naturais encontrados na região de estudo possuem $\mathrm{pH}$ entre 5,2-5,6 enquanto solos agrícolas apresentam pH de 5,8 a 5,9, em razão da aplicação de calagem. A cal hidratada pode aumentar a concentração de cargas negativas $\mathrm{OH}^{-}$na caolinita, refletindo na elevação do $\mathrm{pH}$ e, consequentemente, no crescimento da adsorção (Langmuir, 1997). A substituição de $\mathrm{Mg}$ e Fe pelo $\mathrm{Al}$ faz parte do processo de troca de cátions na caolinita, assim, facilitando a absorção do Al livre no sistema.

$\mathrm{O}$ tratamento estatístico utilizando ACP/AF explicou $89 \%$ do total da variância, gerando quatro componentes (Tabela 2). No processo de análise verifica-se que a componente 1 é a mais importante, pois possui o maior autovalor e variância de 48,3\%. Esta componente está representada pelo autovetor Fator 1. A componente 2 é composta pelos metais $\mathrm{Cr}$, $\mathrm{Ni}$, $\mathrm{Sn}, \mathrm{Pb}, \mathrm{Zn}$ e $\mathrm{Cu}$ formando o Fator 2. Já as componentes 3 e 4 são representadas pelo Fator 3 e Fator 4, respectivamente. A distribuição da nuvem de variáveis mostrou ótima correlação entre os ETR pesados presentes na componente 1 e boa correlação entre as 4 variáveis da componente 3. Já na componente 2 foram observadas boa correlação entre os elementos $\mathrm{Pb}$ Sn e Ni-Cr. Alguns parâmetros identificados como outliers foram removidos da análise, como o molibdênio (Mo) nos pontos amostrais Fx-01 e Fx-02, e o sódio (Na) em Fx-07 e Ma-02, que representaram as maiores discrepâncias.

A relação entre os Fatores permite descriminar 4 grupos originados a partir da similaridade entre os pontos amostrados (Figura 6). O Grupo 1 está representado pelos casos FxBR e Fx-04, demonstrando relação positiva com o Fator 4 (Figura 6C, 6E, 6F). Já o Grupo 2 composto pelos casos Fx-01 e Fx-02 apresenta forte representatividade no Fator 2, sendo marcado pelo distanciamento na abcissa, a partir da origem (Figura 6A, 6D, 6E).

Isso significa que os metais pesados $\mathrm{Cr}$, $\mathrm{Ni}$, $\mathrm{Sn}, \mathrm{Pb}, \mathrm{Zn}$ e $\mathrm{Cu}$ possuem maior influência nos pontos amostrais observados no Grupo 2. O Grupo 3 apresenta relação com o Fator 1, enquanto o Grupo 4 está marcado pela correlação positiva no Fator 3 (Figura 6B). 

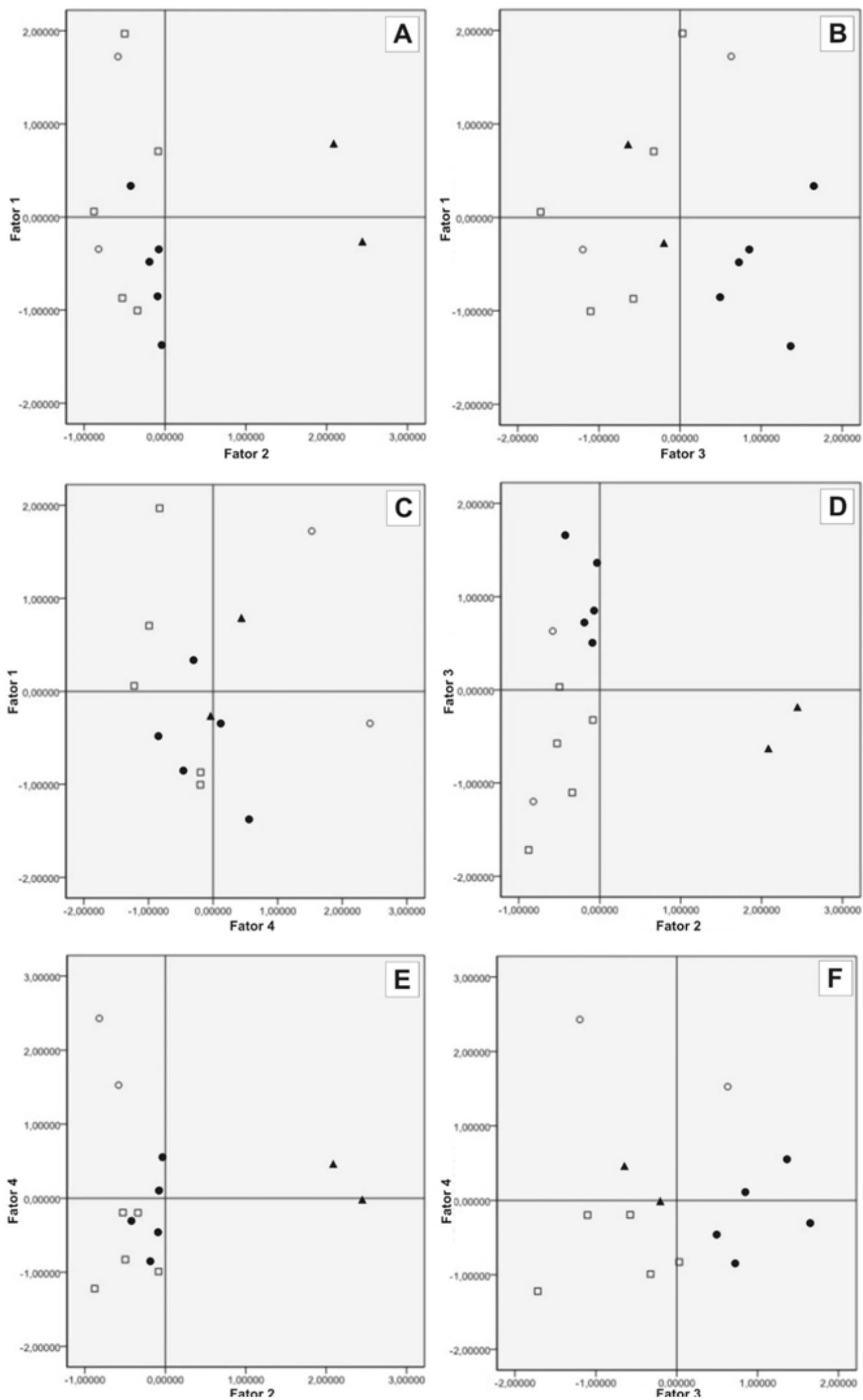

Grupo 1 (Fx-BR, Fx-04)

$\square$ Grupo 3 (Ma-02, Fx-02a, Fx-04a, Fx-03, Fx-05)

$\Delta$ Grupo 2 (Fx-01, Fx-02)

Grupo 4 (Ma-BR, Ma-01, Fx-06, Fx-04b, Fx-07)

Figura 6 - Gráficos bidimensionais representando a relação entre os Fatores e a representatividade dos grupos formados. 
Tabela 2 - Análise de componentes principais pelo Método de extração e método de rotação Varimax com normalização de Kaiser.

\begin{tabular}{l|c|c|c|c}
\hline \multirow{2}{*}{ Parâmetro } & \multicolumn{4}{|c}{ Componentes } \\
\cline { 2 - 5 } Químico & $\mathbf{1}$ & $\mathbf{2}$ & $\mathbf{3}$ & $\mathbf{4}$ \\
\hline Er & 0,989 & $-0,029$ & 0,132 & $-0,044$ \\
Dy & 0,987 & 0,044 & 0,049 & $-0,053$ \\
Yb & 0,986 & $-0,006$ & 0,105 & $-0,080$ \\
Ho & 0,979 & 0,044 & 0,129 & $-0,031$ \\
Tb & 0,979 & 0,077 & 0,116 & 0,063 \\
Sm & 0,976 & 0,062 & 0,076 & $-0,005$ \\
Gd & 0,971 & 0,123 & 0,142 & 0,033 \\
Tm & 0,958 & 0,016 & 0,191 & 0,040 \\
Eu & 0,949 & 0,172 & $-0,053$ & $-0,006$ \\
Pr & 0,917 & 0,160 & 0,212 & 0,094 \\
Nd & 0,896 & $-0,203$ & 0,137 & 0,015 \\
Lu & 0,879 & $-0,219$ & 0,261 & $-0,266$ \\
Se & 0,729 & 0,447 & $-0,025$ & 0,343 \\
As & 0,721 & 0,472 & $-0,217$ & $-0,084$ \\
Fe & 0,713 & 0,385 & $-0,444$ & $-0,221$ \\
Ce & 0,700 & 0,158 & 0,272 & 0,252 \\
Cr & $-0,113$ & 0,956 & 0,116 & 0,084 \\
Ni & $-0,085$ & 0,940 & 0,168 & 0,094 \\
Sn & 0,269 & 0,909 & 0,046 & $-0,117$ \\
Pb & 0,121 & 0,878 & $-0,175$ & $-0,038$ \\
Zn & 0,333 & 0,739 & 0,303 & $-0,249$ \\
Cu & $-0,051$ & 0,703 & 0,083 & 0,023 \\
Ca & 0,046 & 0,038 & 0,953 & $-0,227$ \\
Mg & 0,140 & 0,079 & 0,924 & 0,043 \\
K & 0,178 & 0,107 & 0,898 & $-0,111$ \\
Sr & 0,386 & 0,173 & 0,848 & $-0,173$ \\
Al & $-0,176$ & 0,015 & $-0,143$ & 0,944 \\
Li & 0,261 & $-0,097$ & $-0,219$ & 0,871 \\
\hline & & & & \\
\hline
\end{tabular}

A interpretação dos fatores foi corroborada pela análise de agrupamento visualizado no dendrograma horizontal (Figura 7).

O corte no coeficiente de similaridade 20 descrimina quatro grupos bem definidos. Estes possuem os mesmos integrantes que os grupos formados na ACP/AF, confirmando a homogeneidade.

A maior semelhança dentre os agrupamentos é observada nos casos Fx-02a e Ma-02 pertencentes ao Grupo 3. A menor afinidade demonstrada em relação aos outros foi observada nos pontos Fx-01 e Fx-02, que compõem o Grupo 2, correspondendo à área com maior impacto agrícola.

\section{Geoquímica Multielementar}

As rochas vulcânicas ácidas do Tipo Palmas possuem valores médios de $\mathrm{Cr}$ e $\mathrm{Ni}$ variáveis entre 6-10 ppm e 4-7 ppm, respectivamente (Bellieni et al. 1986). Estas concentrações estão enquadradas no intervalo da Amplitude Interquartil (IQR) observado nos sedimentos das bacias.

Os pontos Fx-01 e Fx-02 apresentam valores externos ao IQR, formando outliers, nos quais $\mathrm{Cr}, \mathrm{Ni}, \mathrm{Cu}, \mathrm{Sn}$ e Pb se enquadram (Tabela 3). O sódio apresentou intervalo de IQR entre 28,54 e 77,82, revelando dois pontos discrepantes Fx$07(141,54)$ e Ma-02 $(86,03)$.

O Fator de Enriquecimento (FE) considerado foi quantificado de acordo com Sutherland (2000) e representado na Tabela 4. Destacam-se o $\mathrm{Na}$, $\mathrm{Sn}$ e $\mathrm{Pb}$ por estarem enquadrados na classificação, como sinais antropogênicos significativos.

Relacionando os elementos químicos outliers observados nos dados estatísticos descritivos e multivariados com os valores de enriquecimento comprova-se que as maiores discrepâncias nas sub-bacias Fx-01, Fx-02 ocorrem nos elementos $\mathrm{Cr}, \mathrm{Ni}, \mathrm{Cu}, \mathrm{Sn}, \mathrm{Pb}$, enquanto o Na, nas sub-bacias Fx-07 e Ma-02.

A elevada concentração e aumento em relação ao background destes elementos pode estar relacionada à capacidade de adsorção dos sedimentos finos constituídos por caolinita e óxidos de ferro, embora, no primeiro caso, o argilomineral tenha menor influência. 


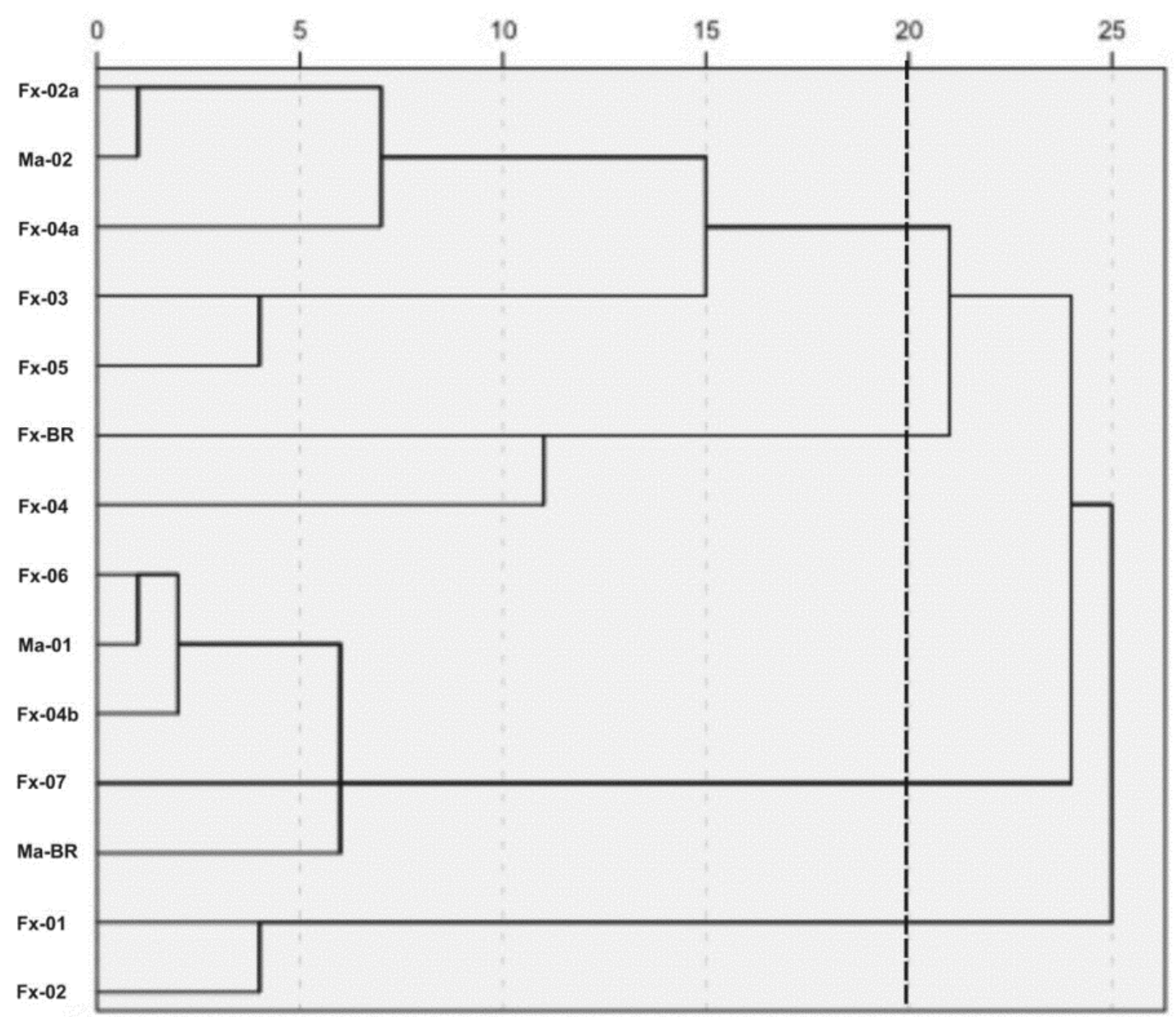

Figura 7 - Dendrograma horizontal, demonstrando o nível de similaridade e a ordem dos agrupamentos.

A concentração dos elementos-traço nos fertilizantes utilizados nas culturas agrícolas da região é apresentada na Tabela 5. Estudos experimentais realizados para determinação da mobilidade dos metais traços em sedimentos fluviais, utilizando água do rio como extrator, apontam a baixa susceptibilidade à desorção de As, $\mathrm{Co}, \mathrm{Cr}, \mathrm{Ni}, \mathrm{Cd}$ e $\mathrm{Pb}$, tendo os dois últimos os menores valores de mobilidade (Villanueva et al., 2013).

Metais pesados como $\mathrm{Pb}, \mathrm{Cu}, \mathrm{Cr}$ e Ni podem ter a mobilidade reduzida no solo pela interação com fertilizantes químicos fosfatados e ureia. Estes resultados foram confirmados por Liu et al. (2007), ao estudar aplicação de ureia e $\mathrm{KH}_{2} \mathrm{PO}_{4}$ no solo, reduzindo drasticamente a mobilidade do $\mathrm{Cu}, \mathrm{Cr}$ e Ni . Por outro lado, a mobilidade do $\mathrm{Pb}$ em solos pode ser também diminuída pela aplicação de fosfatos (Ma et al., 1995).

Metais pesados como $\mathrm{Cu}, \mathrm{Mn}, \mathrm{Zn}$, As e $\mathrm{Pb}$, observados em sedimentos fluviais, podem ter contribuição a partir da aplicação de pesticidas, enquanto adubos orgânicos e fertilizantes contribuem para o aumento de As, Cd, U, P, V, $\mathrm{Cu}, \mathrm{Mn}$ e Zn (Souza, 2005). Os agrotóxicos mais utilizados na agricultura contêm elevadas concentrações de até 22 elementos químicos, sendo mais abundantes $\mathrm{Br}, \mathrm{C}, \mathrm{Cl}, \mathrm{S}, \mathrm{P}, \mathrm{H}, \mathrm{N}, \mathrm{O}$ (Barbosa, 2004).

Outros pesticidas utilizados na agricultura, como os triorganoestanhosos, podem contribuir para o aporte de Sn no sistema.

A calda bordalesa, constituída dominantemente por sulfato de cobre, utilizada na agricultura como fungicida possui outros metais na composição, impurezas, como $\mathrm{Zn}, \mathrm{Pb}, \mathrm{Cr}$, Cd e Ni (Mirlean et al., 2005).

Os mesmos autores desenvolveram estudo abordando a influência da aplicação de calda bordalesa nos solos usados para cultivo de videira (Vitis sp.) no Município de Bento Gonçalves. É possível estabelecer a similaridade entre esta região com a região de Caxias do Sul, em decorrência das condições geológicas e climáticas.

A pesquisa em pauta relacionou a presença destes elementos nos horizontes superficiais de solo (0-5 cm). Kuhn (2011) quantificou a presença desses metais no sulfato de cobre e na cal virgem da calda bordalesa, através de análises por ICP-MS (Tabela 6). 
Tabela 3 - Concentrações dos principais elementos químicos analisados nos sedimentos e os valores outliers identificados na estatística descritiva.

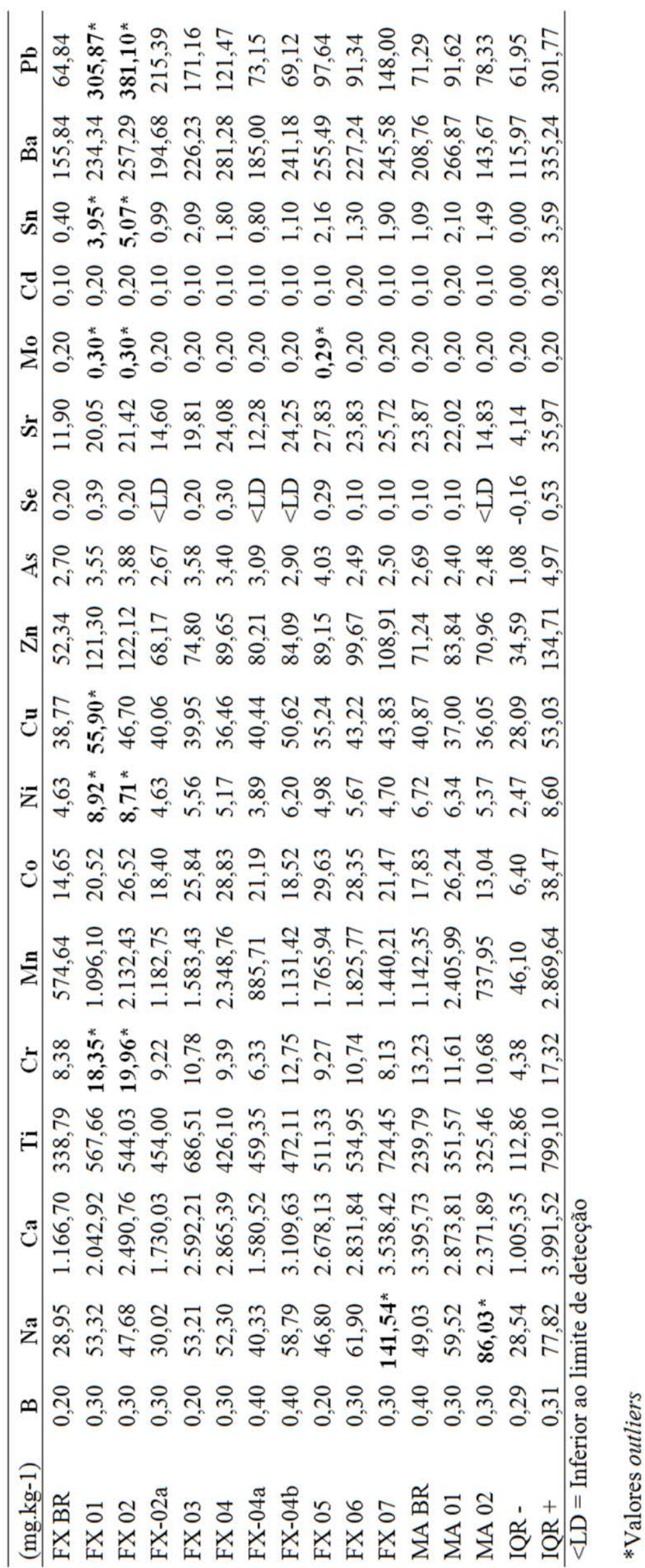


Tabela 4 - Representação dos elementos químicos com Fator de Enriquecimento (FE) > 2.

\begin{tabular}{l|c|c|c|c|c|c|c|c|c|c|c|c|c|c|c|c|c}
\hline Ponto & B & Na & Ca & Ti & Cr & Mn & Co & Ni & Zn & As & Se & Sr & Mo & Cd & Ba & Sn & Pb \\
\hline Fx-01 & --- & 2,2 & 2,1 & 2,0 & 2,7 & 2,3 & --- & 2,3 & 2,8 & --- & 2,4 & 2,0 & --- & 2.4 & --- & $12,0^{*}$ & $5,7 *$ \\
\hline Fx-02 & --- & 2,0 & 2,6 & --- & 3,0 & 4,6 & 2,2 & 2,3 & 2,9 & --- & --- & 2,2 & --- & 2.5 & 2,0 & $15,7 *$ & $7,3^{*}$ \\
\hline Fx-02a & --- & --- & --- & --- & --- & 2,5 & --- & --- & --- & --- & --- & --- & --- & --- & --- & 3,0 & 4,1 \\
\hline Fx-03 & --- & 2,6 & 3,1 & 2,8 & --- & 3,8 & 2,5 & --- & --- & --- & --- & 2,3 & --- & --- & 2,0 & $7,3 *$ & 3,7 \\
\hline Fx-04 & --- & 2,0 & 2,7 & --- & --- & 4,5 & 2,2 & --- & --- & --- & --- & 2,2 & --- & --- & 2,0 & $5,0 *$ & 2,1 \\
\hline Fx-04a & 2,8 & --- & --- & --- & --- & 2,1 & 2,0 & --- & 2,1 & --- & --- & --- & --- & --- & --- & 2,8 & --- \\
\hline Fx-04b & 2,5 & 2,5 & 3,3 & --- & --- & 2,4 & --- & --- & 2,0 & --- & --- & 2,5 & --- & --- & --- & 3,4 & --- \\
\hline Fx-05 & --- & 2,3 & 3,3 & 2,2 & --- & 4,4 & 2,9 & --- & 2,4 & 2,1 & 2,1 & 3,3 & 2,1 & --- & 2,3 & $7,7 *$ & 2,1 \\
\hline Fx-06 & 2,1 & 3,0 & 3,4 & 2,2 & --- & 4,5 & 2,7 & --- & 2,7 & --- & --- & 2,8 & --- & 2,8 & 2,0 & 4,6 & --- \\
\hline Fx-07 & 2,1 & $6,8 *$ & 4,2 & 3,0 & --- & 3,5 & 2,1 & --- & 2,9 & --- & --- & 3,0 & --- & --- & 2,2 & $6,7 *$ & 3,2 \\
\hline Ma-01 & --- & --- & --- & --- & --- & 2,6 & --- & --- & --- & --- & --- & --- & --- & 2,5 & --- & 2,4 & --- \\
\hline Ma-02 & --- & --- & --- & --- & --- & --- & --- & --- & --- & --- & --- & --- & --- & --- & --- & --- & --- \\
\hline
\end{tabular}

Tabela 5 - Concentração dos elementos químicos nos fertilizantes NPK analisados.

\begin{tabular}{l|c|c|c|c|c|c|c|c|c|c|c|c|c|c|c|c}
\hline (mg.kg $^{-1}$ ) & B & Na & Ca & Ti & Cr & Mn & Co & Ni & Cu & Zn & Se & Sr & Cd & Sn & Ba & Pb \\
\hline Fert-01 & 842,0 & $7.472,0$ & $107.754,0$ & 124 & 62,3 & 116 & 1,3 & 8,1 & 44 & 2.638 & 1,6 & 695 & 13,8 & 6,1 & 61,4 & 51,4 \\
\hline Fert-02 & 265,0 & $6.032,0$ & $116.697,0$ & 130 & 92,6 & 250 & 4,3 & 22,9 & 181 & 409 & 1,7 & 398 & 6,9 & 4,5 & 43,4 & 4,4 \\
\hline Fert-03 & 30.9 & $7.403,0$ & $92.403,0$ & 133 & 64,1 & 40,6 & --- & 8,0 & 8,1 & 64,9 & 3,2 & 731 & 11,1 & --- & 26,9 & 2,7 \\
\hline
\end{tabular}

Tabela 6 - Concentração de alguns metais pesados no sulfato de cobre e cal virgem.

\begin{tabular}{|c|c|c|c|c|c|c|}
\hline Amostras (mg.kg ${ }^{-1}$ ) & $\mathrm{Cu}$ & Zn & $\mathbf{P b}$ & Cd & $\mathrm{Ni}$ & $\mathrm{Cr}$ \\
\hline $\mathrm{CuSO}_{4} *$ & 326.000 & 1.309 & 96 & 1,4 & 13 & 20 \\
\hline $\mathrm{CuSO}_{4} * *$ & $>10.000$ & 136,1 & 25,25 & 2,89 & 10,7 & 3,9 \\
\hline Cal Virgem** & 146,93 & 10,6 & 1,03 & 0,02 & 4,5 & 7,1 \\
\hline
\end{tabular}

\section{DISCUSSÃO}

Na bacia de captação Faxinal protocolo estabelecido com os agricultores identificou dez marcas de fungicidas com metais pesados (Dithane, Antracol, Cabrio Top, Manzate, Ridomil Gold, Cobre Atar, Cobre Fersol, além do sulfato de cobre de marcas Agrimar, Inderco, Microsal). A maior aplicação destes agrotóxicos se dá nas sub-bacias Fx-01, Fx-02 e Fx-04, as duas primeiras representando as áreas maiores de cultivo e, consequentemente, com maior volume de aplicação (Tabela 1).

Os elementos químicos que apresentam enriquecimento considerável em relação ao background e destacaram-se como outliers podem ser provenientes de três fontes distintas. Nas sub-bacias Fx-01 e Fx-02, o $\mathrm{Pb}$ e $\mathrm{Sn}$ podem ter origem nos pesticidas e fertilizantes, enquanto $\mathrm{Cr}$, $\mathrm{Ni}$ e $\mathrm{Cu}$ possuem uma condição provavelmente semelhante. Por outro lado, o Pb também pode ser concentrado em razão da aplicação do fertilizante fosfatado, que determina uma imobilidade do metal no solo. As concentrações deste metal não podem ser correlacionadas com sua transferência a partir da litologia aflorante, pois as concentrações no ignimbrito ácido são extremamente baixas, atingindo no máximo $5 \mathrm{mg} \cdot \mathrm{kg}^{-1}$. Entre as anomalias químicas observadas, o chumbo apresentou concentrações superiores aos valores limites determinados pela Resolução CONAMA 420/2009 para investigação, situando-se entre $215 \mathrm{mg} \cdot \mathrm{kg}^{-1}$ (Fx-02a) e 381 mg. $\mathrm{kg}^{-1}$ (Fx-02), contendo a amostra Fx-01, $306 \mathrm{mg} \cdot \mathrm{kg}^{-1}$. Nos demais pontos, com exceção do Fx-04a, os teores oscilaram entre os limites de prevenção (72 mg. $\mathrm{kg}^{-1}$ ) e investigação (180 $\left.\mathrm{mg} \cdot \mathrm{kg}^{-1}\right)$.

A discrepância da concentração de sódio nas amostras Fx-07 e Ma-02 está vinculada ao lançamento de águas residuais e esgoto doméstico irregular. $\mathrm{O} \mathrm{Na}{ }^{+}$trocável disponível em elevadas concentrações no recurso hídrico sofre adsorção pelo sedimento fino. Análises químicas realizadas nas águas superficiais em dois períodos, estiagem e cheias, apontam alta concentração de sódio e elevada condutividade elétrica (Tabela 7). Medeiros et al. (2005), desenvolveram estudo comparativo para 
irrigação de solos, utilizando águas residuais e o método convencional de manejo. Os autores constataram que os efluentes elevam a concentração do $\mathrm{Na}^{+}$no solo devido a adsorção. Outros autores confirmam o aumento de $\mathrm{Na}^{+}$ trocável no solo devido o aporte de águas residuais (Cromer et al., 1984; Smith et al., 1996; Flakiner \& Smith, 1997; Fonseca, 2001 e Garcia, 2003).

Tabela 7 - Valores de $\mathrm{CE}$ e $\mathrm{Na}^{+}$observados nas águas do ponto Fx-07.

\begin{tabular}{l|c|c}
\hline Ponto Fx-07 & $\begin{array}{c}\text { Condutividade a } \\
\mathbf{2 5}^{\mathbf{}} \mathbf{C}(\boldsymbol{\mu S} / \mathbf{c m})\end{array}$ & $\begin{array}{c}\mathbf{N a}^{+} \\
\left(\mathbf{m g . L ^ { - 1 }}\right)\end{array}$ \\
\hline Período estiagem & 196 & 20,5 \\
\hline Background & 20,3 & 1,54 \\
\hline Enriquecimento & 9,6 & 13,2 \\
\hline Período cheia & 210 & 22 \\
\hline Background & 19,7 & 1,5 \\
\hline Enriquecimento & 10,6 & 14,7 \\
\hline
\end{tabular}

O aumento da concentração de alguns metais pesados em sedimentos pode ter origem geogênica, sendo oriundo de remobilização da deposição de fundo por obras de dragagem e retificação de curso do rio (Souza, 2005).

No período de desenvolvimento deste estudo não foram observadas perturbações ao sistema de deposição original dos sedimentos, minimizando a possibilidade de enriquecimento natural por exposição a novas condições de mobilidade, dispersão e precipitação.

No entanto, pode haver contribuição de $\mathrm{Na}$, $\mathrm{Ca}, \mathrm{K}$, e Ti proveniente da ação intempérica sobre feldspatos e minerais metálicos que compõem a paragênese da rocha vulcânica descrita no local.

A distribuição e comportamento dos ETR nas rochas vulcânicas da região pode ser comparada com áreas similares da Bacia do Paraná, como apresentado por vários autores (Bellieni, 1986; Peate, 1997; Umann, 2001; Nardy, 2008).

O comportamento padrão dos ETR nas rochas ácidas do Tipo Palmas apresenta forte enriquecimento em Terras Raras leves (ETRL) e a anomalia negativa de Európio (Eu), é atribuída ao fracionamento de plagioclásio durante a diferenciação (Mantovani et al. 1985a, b).

Os resultados de ETR nas amostras de sedimentos de fundo demonstraram padrão de distribuição similar às rochas Tipo Palmas, com leve depleção, i.e, enriquecimento em ETRL e anomalia negativa de Eu (Figura 7).

Esta redução pode estar associada aos processos intempéricos, lixiviamento do solo por runoff e a oscilação da capacidade de sorção e desorção. Em experimento laboratorial, Wang et al. (2011) observaram a diminuição da concentração de ETR no solo durante evento simulado de runoff, isto ocorreu devido à interação água e solo gerando flutuação nos processos de adsorção-desorção.

A taxa de adsorção pode ser induzida em solos pelos argilominerais, pH, oxidaçãoredução potencial, matéria orgânica e capacidade de troca catiônica (Haygarth et. al., 1998).

A expressão gráfica da distribuição de ETR nos fertilizantes apresenta assimetria em relação aos sedimentos, não sendo possível verificar influência sobre o sistema sedimentar fluvial das bacias de captação Faxinal e Maestra (Figura 8).

O comportamento dos ETR em rochas e sedimentos pode ser avaliado pela inclinação da reta $(\mathrm{La} / \mathrm{Lu})_{\mathrm{N}}$, de tal forma que quanto maior o número, maior o fracionamento das ETRL em relação aos elementos de Terras Raras Pesadas (ETRH).

As rochas do Tipo Palmas, fácies Caxias, possuem razão média $(\mathrm{La} / \mathrm{Lu})_{\mathrm{N}}=7,04$ (Nardy, 2008) Os sedimentos amostrados na área de estudo apresentaram valores de média aritmética de $(\mathrm{La} / \mathrm{Lu})_{\mathrm{N}}=5,39$, mediana $(\mathrm{La} / \mathrm{Lu})_{\mathrm{N}}=5,28$, entrada mínima de $(\mathrm{La} / \mathrm{Lu})_{\mathrm{N}}=4,04$ e entrada máxima $(\mathrm{La} / \mathrm{Lu})_{\mathrm{N}}=6,70$. Por outro lado, as razões $(\mathrm{La} / \mathrm{Lu})_{\mathrm{N}}$ para os fertilizantes mostram valores de 19,65 (Fertilizante 01) e 4,57 (Fertilizante 02), enquanto o Fertilizante 03 é intermediário $(6,19)$.

Os dois últimos tipos respondem pelos padrões mais próximos daquele registrado nos sedimentos de fundo (Tabela 8).

Esta média expõe valores diminuídos em relação ao subtipo Caxias, como já observado no comportamento dos ETR (Figura 8). No entanto, partindo da ótica estatística descritiva as razões $(\mathrm{La} / \mathrm{Lu})_{\mathrm{N}}$ analisadas nas amostras não apresentaram discrepância com o intervalo de variação IQR $(2,46 \quad$ - 8,41) inferindo proveniência vinculada às rochas do Tipo Palmas, indicando fonte geogênica. 


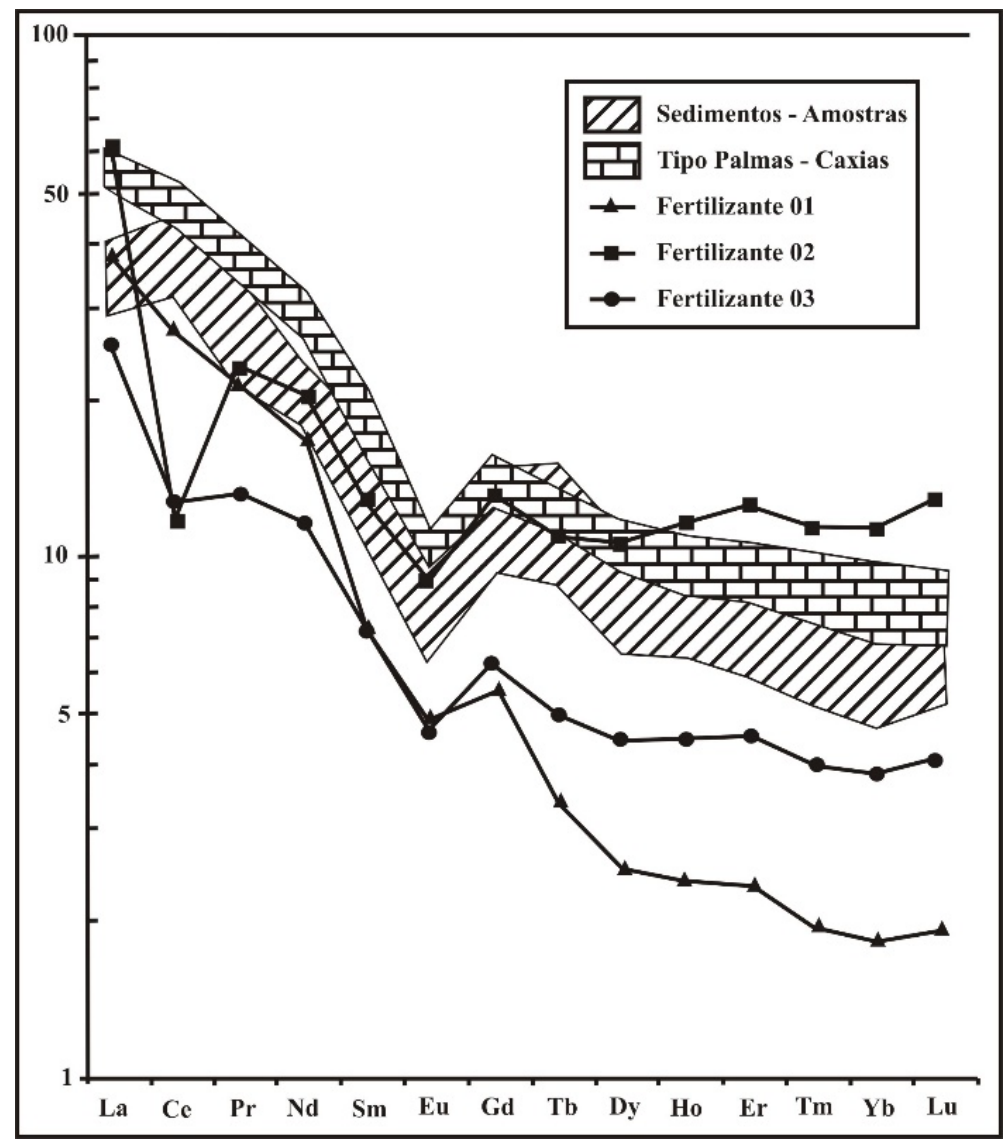

Figura 8 - Comparativo entre ETR identificados nos sedimentos e fertilizantes amostrados, e ETR reconhecidos na rocha Tipo Palmas - fácies Caxias (Peate, 1997; Nardy, 2008). Amostras normalizadas pelos valores do manto primitivo (Sun e McDonough, 1989).

Tabela 8 - Representação dos valores Elementos Terras Raras e La/Lu analisados nos sedimentos, fertilizantes e rocha Tipo Palmas - Caxias*. Amostras normalizadas pelos valores do manto primitivo (Sun e McDonough, 1989).

\begin{tabular}{|c|c|c|c|c|c|c|c|c|c|c|c|c|c|c|c|}
\hline$\left(\mathrm{mg} \cdot \mathrm{kg}^{-1}\right)$ & $\mathrm{La}$ & $\mathrm{Ce}$ & $\operatorname{Pr}$ & $\mathrm{Nd}$ & $\mathrm{Sm}$ & $\mathrm{Eu}$ & $\mathrm{Gd}$ & $\mathrm{Tb}$ & Dy & Ho & Er & $\mathrm{Tm}$ & $\mathrm{Yb}$ & $\mathrm{Lu}$ & $\mathrm{La} / \mathrm{Lu}$ \\
\hline Fx-BR & 35,61 & 39,33 & 25,33 & 19,25 & 12,15 & 7,13 & 10,56 & 10,17 & 7,32 & 7,31 & 6,87 & 6,75 & 5,67 & 5,40 & 6,60 \\
\hline$F x-01$ & 35,89 & 39,18 & 30,38 & 21,35 & 15,77 & 9,98 & 13,57 & 12,79 & 9,50 & 9,62 & 8,43 & 8,00 & 7,00 & 6,66 & 5,39 \\
\hline $\mathrm{Fx}-02$ & 33,41 & 39,86 & 27,00 & 18,42 & 13,20 & 8,28 & 11,50 & 11,04 & 7,95 & 7,88 & 7,04 & 6,71 & 5,84 & 5,37 & 6,22 \\
\hline $\mathrm{Fx}-02 \mathrm{a}$ & 29,91 & 32,45 & 21,48 & 18,39 & 12,02 & 7,06 & 9,61 & 9,15 & 7,10 & 6,63 & 6,17 & 5,34 & 5,01 & 5,34 & 5,60 \\
\hline FX-03 & 35,88 & 42,50 & 28,81 & 21,29 & 14,33 & 8,87 & 12,84 & 11,96 & 9,03 & 9,09 & 8,49 & 8,06 & 7,06 & 8,06 & 4,45 \\
\hline FX-04 & 37,83 & 44,71 & 32,96 & 23,77 & 17,56 & 10,71 & 15,09 & 14,81 & 10,71 & 10,97 & 9,79 & 9,46 & 7,91 & 8,10 & 4,67 \\
\hline FX-04a & 30,47 & 33,41 & 22,39 & 20,25 & 13,47 & 8,31 & 10,70 & 11,08 & 8,52 & 8,51 & 7,48 & 6,74 & 6,27 & 6,74 & 4,52 \\
\hline FX-04b & 33,59 & 37,03 & 23,53 & 21,25 & 13,50 & 8,33 & 10,73 & 11,10 & 8,13 & 7,92 & 7,28 & 6,75 & 5,88 & 6,75 & 4,98 \\
\hline FX-05 & 37,59 & 39,06 & 33,80 & 23,50 & 17,91 & 11,11 & 14,99 & 14,55 & 10,93 & 10,78 & 10,02 & 9,29 & 8,37 & 9,29 & 4,05 \\
\hline FX-06 & 34,98 & 36,01 & 26,01 & 19,52 & 12,58 & 7,12 & 11,21 & 10,16 & 7,71 & 7,90 & 7,27 & 6,74 & 6,07 & 6,74 & 5,19 \\
\hline FX-07 & 38,84 & 42,23 & 30,05 & 21,26 & 14,41 & 7,73 & 12,58 & 12,03 & 8,68 & 9,14 & 8,33 & 8,10 & 6,89 & 8,10 & 4,79 \\
\hline Ma-BR & 34,05 & 32,25 & 22,00 & 18,38 & 11,21 & 6,52 & 9,52 & 9,22 & 6,62 & 6,68 & 6,01 & 5,38 & 4,85 & 5,38 & 6,33 \\
\hline Ma-01 & 32,84 & 38,86 & 22,79 & 18,36 & 12,14 & 7,13 & 10,22 & 9,24 & 7,31 & 7,30 & 6,65 & 6,74 & 5,47 & 5,40 & 6,09 \\
\hline Ma-02 & 36,01 & 33,81 & 24,12 & 20,54 & 12,31 & 7,10 & 10,33 & 9,20 & 6,87 & 6,66 & 6,42 & 5.37 & 5,04 & 5,37 & 6,71 \\
\hline Peate & 58,37 & 47,72 & $\mathrm{NI}^{* *}$ & 29,54 & 18,09 & 9,52 & $\mathrm{NI}^{* *}$ & 11,11 & $\mathrm{NI}^{* *}$ & $\mathrm{NI}^{* *}$ & $\mathrm{NI}^{* *}$ & $\mathrm{NI} * *$ & 7,69 & 7,30 & 8,00 \\
\hline Nardy-kse & 50,95 & 42,82 & $\mathrm{NI}^{* *}$ & 26,59 & 15,77 & 9,88 & 12,25 & $\mathrm{NI} * *$ & 9,36 & 8,54 & 8,33 & $\mathrm{NI} * *$ & 6,90 & 6,76 & 7,54 \\
\hline Nardy-kpt & 58,22 & 51,83 & $\mathrm{NI}^{* *}$ & 32,50 & 20,95 & 10,95 & 15,44 & $\mathrm{NI} * *$ & 11,94 & 10,98 & 10,63 & $\mathrm{NI} * *$ & 9,74 & 9,46 & 6,16 \\
\hline Fert_01 & 37,52 & 27,16 & 21,67 & 16,67 & 7,36 & 4,89 & 5,52 & 3,39 & 2,52 & 2,37 & 2,35 & 1,95 & 1,83 & 1,91 & 19,66 \\
\hline Fert_02 & 59,60 & 11,72 & 23,03 & 20,33 & 12,78 & 8,94 & 13,09 & 10,94 & 10,62 & 11,61 & 12,40 & 11,37 & 11,44 & 13,04 & 4,57 \\
\hline Fert_03 & 25,59 & 12,71 & 13,28 & 11,69 & 7,16 & 4,65 & 6,29 & 4,97 & 4,43 & 4,49 & 4,55 & 4,00 & 3,84 & 4,13 & 6,19 \\
\hline
\end{tabular}

*Fonte: Peate (1997); Nardy (2008).

**NI = não informado. 


\section{CONCLUSÃO}

Os sedimentos ativos dos córregos da bacia de captação Faxinal expõem contaminação e efeito acumulativo por metais pesados provenientes da aplicação de fertilizantes e fungicidas.

O chumbo apresentou valores elevados na maioria dos pontos monitorados, destacando-se os pontos Fx-01, Fx-02 e Fx-02a que ultrapassaram o limite para investigação (Resolução CONAMA n ${ }^{\circ}$ 420/2009). No ponto Fx-02 a concentração do $\mathrm{Pb}$ excedeu o dobro do valor referido para investigação, tornando-se crítico ao meio ambiente.

A adsorção dos elementos outliers provavelmente está vinculada à presença de óxidos de ferro e caolinita nos sedimentos finos, atuando como uma barreira geoquímica à migração dos metais. Este processo é particularmente favorecido pela capacidade de sorção em condições de $\mathrm{pH}$ neutro à alcalino.

A anomalia de sódio nos sedimentos finos, provavelmente relacionada com a descarga direta de esgoto doméstico nos córregos, também está relacionada com os processos de sorção mencionados anteriormente.

Os resultados de ETR presentes nos sedimentos de fundo remetem à origem geogênica, não sendo possível rastrear a interferência dos fertilizantes NPK aplicados ao longo das bacias estudadas.

\section{AGRADECIMENTOS}

Os autores agradecem ao Serviço Autônomo Municipal de Água e Esgoto (SAMAE) de Caxias do Sul, RS, pelo financiamento e apoio logístico para o desenvolvimento desta pesquisa.

\section{REFERÊNCIAS}

BARBOSA, L.C.A. Os pesticidas, o homem e o meio ambiente. Viçosa. Ed. UFV, 2004. 215p.

BELLIENI, G.; COMIN-CHIARAMONTI, P.; MARQUES, L. S.; MELFI, A.J.; PICCIRILLO, E.M.; NARDY, A.J.R.; ROISENBERG, A. High- and low-Ti flood basalts from the Paraná plateau (Brazil): petrology and geoquimical aspects bearing on their mantle origin. Neues Jahrbuch für Mineralogie, v. 150, p. 273-306, 1984.

BELLIENI, G.; COMIN-CHIARAMONTI, P.; MARQUES, L. S.; MELFI, A.J.; NARDY, A.J.R.; PAPATRECHAS, C.; PICCIRILLO, E.M.; ROISENBERG, A.; STOLFA, D. Petrogenetic aspects of acid and basaltic lavas from the Paraná Plateau (Brazil): geological, mineralogical and petrochemical relationships. Journal of Petrology, v. 27, Part 4, p. 915-944, 1986.

BETIOLLO, L.M. Caracterização estrutural, hidrogeológica e hidroquímica dos Sistemas Aquíferos Guarani e Serra Geral no nordeste do Rio Grande do Sul, Brasil. Porto Alegre, 2006. 116p. Dissertação (Mestrado em Geologia). Instituto de Geociências, Universidade Federal do Rio Grande do Sul.

BRITO, L.T.L.; SRINIVASAN, V.S.; SILVA, A.S.; GHEYI, H.R.; GALVÃO, C.O.; HERMES, L.C. Metais pesados nos solos e nos sedimentos depositados nas fontes hídricas da bacia hidrográfica do rio Salitre. In: CONGRESSO BRASILEIRO DE ENGENHARIA AGRÍCOLA, XXXIII, 2004, São Pedro. Anais...São Pedro: SBG, 2004.

CHARALAMPIDES, G. \& MANOLIADIS, O. $\mathrm{Sr}$ and $\mathrm{Pb}$ isotopes as environmental indicators in environmental studies. Environment International, v. 28, p. 147-151, 2002.

CONAMA. Resolução n $^{\circ} 420$, de 28 de dezembro de 2009. Publicado DOU no 249, de 30/12/2009, págs. 81-84. Disp. em: $<$ http://www.mma.gov.br/port/conama/legiabre.cfm?codlegi=6 20>. Acesso em: 19 jun2015.

CROMER, R.N.; TOMPKINS, D.; BARR, N.J.; HOPMANS, P. Irrigation of Monterey pine with wastewater: effect on soil chemistry and groundwater composition. Journal of Environmental Quality, Madison, v. 13, n. 4, p. 539-542, 1984.

CUNHA, S.B. Geomorfologia Fluvial. Em: GUERRA, A.J.T.;
CUNHA, S.B. Geomorfologia: uma atualização de bases e conceitos/organização. $7^{\text {a }}$ Ed. Rio de Janeiro: Bertrand Brasil, 2007. 472p.

FALKINER, R.A. \& SMITH, C.J. Changes in soil chemistry in effluent-irrigated Pinus radiate and Eucalyptus grandis. Australian Journal of Soil Research, Victoria, p. 131-147, 1997.

FONSECA, A.F. Disponibilidade de nitrogênio, alterações nas características químicas do solo e do milho pela aplicação de efluente de esgoto tratado, Piracicaba, 2001. 110p. Dissertação (Mestrado em Agronomia), Escola Superior de Agricultura Luiz de Queiroz.

FRASCA, A.A.S. \& LISBOA, N.A. Contribuição do sensoriamento remoto na compartimentação morfotectônica e morfoestrutural da bacia do Paraná “Grupo São Bento”, RS, e suas relações com as estruturas regionais do embasamento. In: SIMPÓSIO BRASILEIRO DE SENSORIAMENTO REMOTO, VII, 1993, Curitiba. Anais...Curitiba: SBG, p. 211220, 1993.

GARCIA, G.O. Alterações químicas, físicas e mobilidade de íons no solo decorrentes da aplicação de água residuária da lavagem e despolpa dos frutos do cafeeiro conilon. Viçosa, 2003. 100p. Dissertação (Mestrado em Agronomia), Ciências Agrárias, Universidade Federal de Viçosa.

HAYGARTH, P.M.; HEPWRTH, L.; JARVIS, S.C.; Forms of phosphorus transfer in hydrological pathways from soil under grazed grassland. European Journal of Soil Science, v. 49, p. 65-72, 1998.

IBGE - Instituto Brasileiro de Geografia e Estatística. Projeto RADAMBRASIL: Folha SH.22 Porto Alegre e parte das folhas SH.21 Uruguaiana e SI. 22 Lagoa Mirim: geologia, geomorfologia, pedologia, vegetação, uso potencial da terra. IBGE, v. 33, Rio de Janeiro, 1986.

KAISER, H.F. The varimax criterion for analytic rotationing factor analysis. Psychometrika, v. 23, p. 187-200, 1958.

KUHN, I.A. Análise multi-elementar e transferência de metais e isótopos de chumbo no sistema planta-solo-água subterrânea em área contaminada por calda bordalesa na região vinífera de Palomas, município de Santana do Livramento, RS. Porto Alegre, 2011. 83p. Trabalho (Monografia de Conclusão de Curso em Geologia), Instituto de 
Geociências, Universidade Federal do Rio Grande do Sul.

LANGMUIR, D. Aqueous environmental geochemistry. Prentice-Hall, Inc. 1997. 602p.

LARSON, R. \& FABER, F. Estatística aplicada. Tradução VIANNA, L.F.P. $4^{\mathrm{a}}$ Ed. São Paulo: Person Prentice Hall, 2010. Título original: Elementary Statistics. 640p.

LIMA, E.F; PHILIPP, R.P; RIZZON, G.C.; WAICHEL, B.L.; ROSETTI., L.M.M. . Sucessões Vulcânicas e Modelo de Alimentação e Geração de Domos de Lava Ácidos da Formação Serra Geral na Região de São Marcos-Antonio Prado (RS). Geologia USP. Série Científica, v. 12, p. 49-64, 2012.

LIU, J.; DUAN, CHANG-QUN.; ZHU, YI-NIAN.; ZHANG, XUE-HONG.; WANG, CHENG-XIAN. Effect of chemical fertilizers on the fractionation of $\mathrm{Cu}, \mathrm{Cr}$ and $\mathrm{Ni}$ in contaminated soil. Environmental Geology, v 52, p. 1601-1606, 2007.

MA, L.Q, LOGAN T.J, TRAINA S.J. Lead immobilization from aqueous solucions and contaminated soils using phosphate rocks. Environmental Science \& Technology, v. 29, p. 11181126, 1995.

MANTOVANI, M.S.M.; MARQUES, L.S.; SOUSA, M.A.; CIVETTA, L.; ATALLA, L.; INNOCENTI, F. Trace element and strontium isotope constraints on the origin and evolution of Paraná continental flood basalts of Santa Catarina state (southern brazil). Journal Petrology, v. 26, p. 187-209, 1985(a).

MANTOVANI, M.S.M.; CORDANI, U.G.; ROISENBERG, A. Isotope geochemistry of acidic volcanics from the Paraná basin and petrogenetic implications (in Portuguese) Revisit University of Tasmania, 198p, 1985(b).

MEDEIROS, S.S.; SOARES, A.A.; FERREIRA, P.A.; NEVES, J.C.L.; MATOS, A.T.; SOUZA, J.A.A. Utilização de água residuária de origem doméstica na agricultura: Estudo das alterações químicas do solo. Revista Brasileira de Engenharia Agrícola e Ambiental, v. 9. n. 4, p.603-612, 2005.

MENDES, M.A.M.; LEITE, M.G.P.; LENA, J. C. Assinatura geológica e influência do uso e da ocupação do solo na geoquímica de águas e sedimentos da bacia do ribeirão Caraça, Catas Altas, MG. Geochimica Brasiliensis, v. 27, n. 2, p. 120129, 2013.

MIRLEAN, N.; ROISENBERG, A.; CHIES, J.O. Copper-Based Fungicide Contamination and Metal Distribution in Brazilian Grape Products. Bulletin of Environmental Contamination and Toxicology, v. 75, n. 1, p. 968-974, 2005.

NARDY, A.J.R.; MACHADO, F.B.; OLIVEIRA, M.A.F. As rochas vulcânicas mesozoicas ácidas da Bacia do Paraná: litoestratigrafia e considerações geoquímico-estratigráficas. Revista Brasileira de Geociências, v. 38, n. 1, p 178-195, 2008.

PEATE, D.W. The Paraná-Etendeka Province. In: MAHONEY J.J. \& COFFIN M.F (Eds.) Large igneous provinces: continental, oceanic and planetary flood volcanism. Geophys, v. 100, AGU, p. 217-245, 1997.
RIO GRANDE DO SUL. Zoneamento ambiental da silvicultura: estrutura, metodologia e resultados. Volume I. Porto Alegre. 2010. Disp. em: http://www.fepam.rs.gov.br/biblioteca/silvicultura/V1_ZAS\%20APROVADO\%20CONSOLIDADO\%20C ORRIGIDO\%20V-18-05-2010.pdf. Acessado em: 26mar2016.

ROISENBERG, A. Petrologia e Geoquímica do Vulcanismo Ácido Mesozoico da Província Meridional da bacia do Paraná. Porto Alegre, 1990. 285p. Tese (Doutorado em Geologia), Instituto de Geociências, Universidade Federal do Rio Grande do Sul.

ROISENBERG, A. \& VIERO, A.P. O Vulcanismo Mesozóico da bacia do Paraná no Rio Grande do Sul. In: HOLZ, M; DE ROS, F; Geologia do Rio Grande do Sul. (Eds) - Porto Alegre: CIGO/UFRGS Porto Alegre, 2000, 444p.

SMITH, C.J.; HOPMANS, P.; COOK. F.J. Accumulation of Cr, $\mathrm{Pb}, \mathrm{Cu}, \mathrm{Ni}, \mathrm{Zn}$ and $\mathrm{Cd}$ in soil following irrigation with treated urban effluent in Australia. Environmental Pollution, v. 94, n. 3, p. 3 17-323, 1996.

STRECK, E.V. Solos do Rio Grande do Sul. Porto Alegre: EMATER/RS-ASCAR. 2ed. 222p, 2008.

SUN, S. \& MCDONOUGH, W.F. Chemical and isotopic systematics of oceanic basalts: implications for mantle composition and processes. In: A.D. Saunders, M.J. Norry (Eds), Magmatism in the oceanic basins. Geol. Soc. Lond. Spec. Pub., p. 313-345, 1989.

SUTHERLAND, R.A. \& TOLOSA, C.A. Multi-element analysis of road-deposited sediment in an urban drainage basin, Honolulu, Hawaii. Environmental Pollution, v. 110, p. 483495, 2000.

TORRES, A.M.; BASTOS, M.L.L.; BOAVENTURA, G.R.; LICHT, O.A.B.; KERN, D.C.; JUNIOR, G.M.; FRAZÃO, F.J. L.; COSTA, M.L.; BORBA, R.P.; FIGUEIREDO, B.R.A geoquímica dos sedimentos e solos. In: SOUZA, C.R.G.; SUGUIO, K.; OLIVEIRA, A.M.S.; OLIVEIRA, P.E.; Quaternário do Brasil. Ribeirão Preto. Ed. Holos, 382p, 2005. UMANN, L.V.; LIMA, E.F.; SOMMER, C.A.; LIZ, J.D. Vulcanismo ácido da região de Cambará do Sul, RS: litoquímica e discussão sobre a origem dos depósitos. Revista Brasileira de Geociências, v. 31, n. 3, p. 357-364, 2001.

VILLANUEVA, U.; RAPOSO, J.C.; MADARIAGA, J.M. A new methodological approach to assess the mobility of As, Cd, Co, $\mathrm{Cr}, \mathrm{Cu}, \mathrm{Fe}, \mathrm{Ni}$ and $\mathrm{Pb}$ in river sediments. Microchemical Journal, v. 106, p. 107-120, 2013.

WANG, L.; LIANG, T.; KLEINMAN, P.J.A.; CAO, H. An experimental study on using rare earth elements to trace phosphorous losses from nonpoint sources. Chemosphere, v. 85, p. 1075-1079, 2011

Submetido em 17 de novembro 2016 Aceito em 17 de janeiro de 2018 